\title{
Research on Interest and Accepting Psychology of College Freshman Year in Art Design Education
}

\author{
Pingqing Zhang \\ Arts College \\ Yantai Nanshan University \\ YanTai, LongKou, China \\ e-mail: hit_2007@163.com
}

\author{
Yang Wang \\ Arts College \\ Yantai Nanshan University \\ YanTai, LongKou, China \\ e-mail:nsxy2008@163.com
}

\begin{abstract}
On the old teaching, the teacher defined as imparter and educator and administer of knowledge is center status. Under the mode, the student's interest are ignored or looked upon them oneself, so the accepting effect often is ignored, and the teaching effect discount and mislead and cause harm to the student. Research on the being and change of the student's interest is not only the teaching method, but change by the center of teacher into by the center of the student, in order to adapt the need of bringing up person with innovated design.
\end{abstract}

Keywords-interest; college freshman; accepting effect; accepting psychology

\section{INTRODUCTION}

Interest, is a kind of psychological response in the process of information acceptance, and is closely related to whether or not to accept it and whether to take action and efficiency of action and the quality of behavior. In teaching, students' interest is psychological variables closely related of the creation and reception, psychological formation and changes.

In the old teaching model, teachers tend to be defined as "a knowledge giver", "teaching", "management" and "transformation", in every link of the teaching center position or dominant position, which leads to the teaching process completely according to their own idea, intention, experience and methods they think students "should learn" stuff to students, whether you are willing or not to be, or should be through what channels and ways to, must obey, must reach the set standard.

The design education of 21 century is no longer in a given culture, unified standard to measure the "qualified", but in view of the highly dynamic social and the needs of the times, not to stick to one pattern to cultivate or "with a" vibrant innovators. In this sense, the "Teacher centered" "pass by" mode to "take the student as the center" and "communication" mode is an important task.

Investigation shows that students' learning interest is not constant in the whole learning process, with the influence from the society and with the learning process, the students interest fluctuates according to different teaching contents and teachers and teaching methods and change the teaching environment and class atmosphere; if only the teaching content, conservative old rigid teaching mode, students' interest in learning will be big margin: even if being the teaching method and the new content, there are a number of students interested in decline due to the existence of some is not perfect.

According to the comprehensive analysis of survey and other related psychological investigation on the students learning interest, after the students to big three, the purpose of learning will further differentiation, if still in the same pattern and content of indoctrination, there will be about $70 \%$ of the students are in a negative or half the apathetic attitude to follow the process of teaching, lack of enthusiasm, but can allowed to graduate.

It is a truth universally acknowledged, if this situation is not changed, be quite different results educators desire will be true. In this sense, research on the interest of learning is a problem that can not be ignored.

\section{THE CHANGES OF INTEREST IN LEARNING}

Interest in learning is a psychological phenomenon of complex and full of dynamic, and is different due to factors of spatial and temporal and different people. In this paper, only the learning interest changes most students in different learning periods and should be noted for the start of the basic way, related factors and learning interest and inspire interest.

Learned from the investigation, interest in learning of the students in different years have different performance. In general, "there is a strong interest in the last semester of freshman, a little disappointed next semester; the sophomore is a fresh feeling, but do not know what to learn; the junior know the importance of each course and why to learn, but is no energy and no interest".

Based on this reflection, the following points should be noted:

1. Almost all the new students for the new school life has a strong interest in maintaining and strengthening, has very important significance to study their interest in, and some foreign universities attach great importance to the study on the "Freshman year";

2. Interest in the recurrence is associated with "began" arouse expectation, interests is Closely related to expectations; 
3. If the teaching activities is regarded as communication activities, it is can not be ignored for each course teaching system of objective, interaction, learning methods of implementation and effective psychological preparation; In this sense, interest in teaching the local and stimulating is fragile, interest is basic way to maintain and sublimation is teaching the overall structure of the update and effective.

\section{ANALYSIS OF THE IMPACT OF INTEREST IN THE PSYCHOLOGICAL AND ENVIRONMENTAL FACTORS}

\section{A. Expectation}

Expectation is a positive mental state, and directly induce the required information search, the expectation is fragile and dynamic, differences due to realistic condition and the result of the strengthened or transformed or even disappear.

Entering university is another new starting point of life, the expectation is produced effect in this new "began". In the survey, the new kind of slightly naughty to university life and answer to "what is the ideal campus life" can see that they had just entered the school's expectations. Survey reflect the strong interest of the first semester, and is closely related to the.

In the learning process, the teaching contents, different teachers teaching level and methods, the class differences between the formation of various relations, teaching plan and relatively strict mandatory will and some expectation difference; Produced by a variety of reasons stress or find themselves neglected or are denied both objective and subjective factors, also can make a part of students lose interest in learning. If the teaching contents and teaching methods of the course of old, opposite or duplicate content as well as to the voice of the students turn a deaf ear to, interest in learning will be a large area and large drop.

The second semester will appear psychological "began", but this mentality for the first semester of study interest "loss" the extent to which has different intensity, once the interest rate again disappeared, new interest again will be greatly reduced. Thus, the new year can not be overlooked is the "psychological sensitive period", plays a very important role in the next step of learning.

\section{B. Objective}

Investigation shows "understanding the meaning of curriculum is interested in". It is also found that the reason is interested in a course answering "for future workers useful" accounted for $70 \%$, it is higher than other reason. Thus, a clear purpose will increase initiative accepted, be strong interest; in addition, feeling useful is the main basis to judge, and is also one of the important sources of interest.

\section{Sense of achievement}

In recent years, "the relationship between appreciation and developing talent" has drawn more and more attention; the famous "Pygmalion Effect" also pay attention to "focus", and "encourage" and the affinity of the interaction between teachers and students. In accepting the psychological investigation, the students also experience the "has the sense of achievement will be interested".
Sense of achievement is the confidence of power, is confirmed and predict the possibility of their ability and success. that confidence has been verified will produce great self motivated and indescribable pleasure, this is the best state of mind to create.

\section{Way of thinking}

The way of thinking cannot ignore the connection with interest formation, Facing the same kind of new things or knowledge, it will also have the difference in interest because of previous knowledge and experience accumulation condition and the different ways of thinking.

The way of thinking of The students are closely related many other effects of their past environment, education and education mode, knowledge structure and they are now located big environment. Students have a different way of thinking is often one of the reasons for the different responses to the same course and The same kind of teaching way. If students are constrained by the past learning without proper guidance to implement new conversion, and is due to the inherent thinking but not to suggest new ways of thinking, that cannot be timely guidance, interest in learning will fall.

\section{E. Environmental factors}

In the process of teaching, it is generally easy to pay attention to assessment of the teaching content and teaching methods and student work, and ignore the non visible environment effect.

Environment and specific "environment" factors combined out is one of the decisive factors in the formation of different psychological situation, which is closely related with the interest in learning.

\section{The environment of campus}

On the surface, Completing the task of learning is achieved through the exam and teacher to fulfill all the teaching content. But it is not the essence of university learning, because selfstudy can also achieve the above results. One of the differences between university learning and self-study is the guidance and inspiration, evaluation function of teachers. Second is the mutual influence of campus environment atmosphere between students, the role of the latter is influence character by environment, and is not easy to detect, but its meaning is not to be ignored.

The influence of environment on the awareness and behavior is everywhere. The different environmental atmosphere will influence the learning and the activity and life of the people. Being their own particular campus environment of each school is a sensible and unspeakable culture, which is one of the important conditions affect the activities in which people's emotion, motivation, thinking and action.

\section{The environment of class}

Class is the basic unit of the school, and is the implementation of professional teaching team, and is the environmental conditions on the most direct impact of each member. On a class, The Class atmospherehas become an important factor influencing the learning interest. 


\section{PROMOTING INTEREST IN LEARNING}

\section{A. Freshman Year}

If four years of undergraduate education as a whole, the first year is the foundation part of the whole. Farming is " spring is the time of the year" experience. The freshman year is a key role in operations as breeding, planting, and is firstly reflected in how to build a foundation for professional learning lay the foundation for the "primary level curriculum" framework; The second is the basic course can lay the foundation for the professional course; The third is how to achieve the purpose of foundation.

The first and second point directly involves the purpose of teaching. Four years of undergraduate teaching is as the basic ability to lay a solid foundation for designers of old, and provide a method for strengthening the ability. The basis and method of training should be a different levels and different kinds of knowledge constructed "purposiveness" teaching system. In this system, basic courses and specialized courses divided into low level, level and high level of training content are according to a certain percentage of interpenetration, and forming from low to high basic training and application training "cycle" to promote the basic ability, and according to the early, high levels of gradual growth.

Third point is the investigation refered to the teaching method. After the teaching objectives and content determination, if the freshman year still like " $1+1=2$ " that repeat procedures and methods, students will lose the confidence of learning and teaching in the traditional teaching of respect. If the content and the methods that they contact are unique and has great appeal, the interest driven learning desire will become the starting point of the second year. of good habits and the way of thinking formed in the freshman year is very important effect for future study and further work.

In this sense, the freshman year should not only lays a foundation for learning content in the future, but also guides and inspires in the students pay attention to teaching structure content and method of the new implementation process.

\section{B. Thinking}

It can obtain the ideal effect in the training of thinking and into every aspect of training in the initial level training of the freshman year. This approach is from the start to inspire students to think.

\section{Thought?}

This problem seems boring, but do well is very interesting. Each day seems to think, but think about it carefully, many times you did not "want to think". Inspire students to start from small things look around, find and accumulation of nutrient, inspired to " think ", "want to" and "think" habits, is to promote the "beginning of wisdom" development.

\section{Think of its value}

Usually people tend to want to go according to the method of their own familiar, and to Choice and Judge Only by your own mind "experience store graphics". For a designer must break through this method should be good at any time and place to find others "worthless" things contains nutrition and problems.

\section{3. "Thinking" running through each link of teaching}

That guiding the students' " do while thought " and " watch and think " and " listen to " and " said to " is a basic way in each teaching link to mobilize the enthusiasm, improve thinking about the validity.

\section{Communication}

The survey shows that students come to resent the boring theory and preach to the teacher as the leading, and is interested in the interesting and not hard mind to understand truth, At the same time, students love the teachers of patience and considerate, friendly, flexible, prompt response to students' homework evaluation fair and "pierce to the heart of the matter". So to create an equality between teachers and students interactive communication teaching method is student expectations.

Usually any normal person has their own advantages. One of the important task of the teacher is to find the advantage and its inspiration and strengthening. So the equality between teachers and students is not a product, but on the premise that every one of the students thought flash point, must show genuine respect for this advantage. Because of this respect is sincere, teachers have a genuine and sincere desire to experience nature will own to help this advantage the understanding and development, so it has great appeal, teachers' ability and force of character will play the role of good relationship between teachers and students, the natural formation.

\section{Exploration}

No exploration is no creation. creation is the result of exploration. the desire of students exploration and the understanding of the method is a product of good attitude. exploration does not depend on one or more of the class that will be able to work, and must start from the first lesson of the freshman year, and runs through the whole process of learning.

Exploration being the same with creativity is not instilled, and is only inspired and induced. Such as the affinity between teachers and students, the operation of interest caused by the ingenious and enlightening role hints and necessary express conditions are likely to become the driving force of students to explore. The students gained strong exploring spirit will be interested in everything, which has significance.

In recent years, reports and comments of adolescents about congenital ability weakening on the newspaper is caused the attention by the education sector and the whole society.

In the art design education, we are starting from the student's instinct and interest, and let them to think more freely, and not be the problem of merits and demerits in their creative attempt, and will be valued as long as the intention to want to do ".... Perhaps it is would be different in the teaching of design. If the educator has become a "child", the effect will be incalculable! 


\section{REFERENCES}

[1] Shiyuan Wu. From The "Deconstruction" To "Structure"[C].BeiJing: The Forum Of China International Industrial Design and symposium (CICID), 2003.9

[2] Killlon, J. P. \& Tdonem, G. R. (1993). A process for personal theory bui lding. In: Woolfolk, A. E. (ed.) Readings \& Cases in Educational Psych ology. Boston: Allyn and Bacon

[3] Jianqun Lin. Research On The Teaching Mode Of Research Universities In The Freshman Year[Z]. Chinese Association of higher education "fifteen" of higher education and scientific research.2005.12

[4] Don Hamachek (1990). Psychology Teaching, Learning and Growth, A Division of Simon \& Schuster, Inc.

[5] Jie Liu. From "Passive To Active" -- Discussion To The Meaning Of The Teaching Of Design In Engineering Colleges. BeiJing: The Forum Of China International Industrial Design and symposium (CICID), 2003.9

[6] Gibson, J. T. \& Chandler, L. A. (1988). Educational psychology: Mastering Principles and applications. Massachusetts: Allyn and Bacon, Inc.

[7] Woolfolk, A. (2004). Educational Psychology (9th ed.). Pearson Educati on, Inc 